\title{
Preparation and Evaluation of Fixed Combination of Ketoprofen Enteric Coated and Famotidine Floating Mini Tablets by Single Unit Encapsulation System
}

\author{
Mahipal Reddy Donthi, Narendar Reddy Dudhipala, Devendhar Reddy Komalla, Dinesh Suram and Nagaraju Banala* \\ University College of Pharmaceutical Sciences, Kakatiya University, Warangal, Telangana, India
}

\begin{abstract}
Ketoprofen is a non steroidal anti inflammatory drug and famotidine is a $\mathrm{H}_{2}$ receptor antagonist. The patients with immune mediated diseases like rheumatoid and osteo arthritis treated with ketoprofen, which induces ulcers in the stomach by the stimulation of $\mathrm{H}_{2}$ receptor and inhibition of COX-I enzyme. Upon the addition of famotidine suppress the acid secretion in the stomach, this mechanism was implemented by the delivery system at different time periods with different site specificity in the GIT and drug release was programmed according to the $\mathrm{pH}$ dependent solubility and also includes reducing the cost. Hence, the content of this investigation was to prepare and evaluate the famotidine floating and ketoprofen enteric coated mini tablets capsulated in a single unit dosage form. The tablets were prepared by wet granulation method using HPMC $\mathrm{K}_{100} \mathrm{M}$ and $\mathrm{HPMC}_{15} \mathrm{M}$ as release controlling polymers. Pre compression and post compression parameters of prepared tablets were evaluated as per pharmacopeial methods. From the in vitro release studies, optimized formulation of famotidine floating and ketoprofen enteric coated tablets has shown $98.02 \pm 2.79 \%$ and $97.5 \pm 2.08 \%$ release in $12 \mathrm{~h}$, respectively. Floating lag time of optimized famotidine formulation was $13 \mathrm{sec}$ with total floating time of $>12 \mathrm{~h}$ and ex vivo retention time was found to be $12 \mathrm{~h}$. SEM studies were conducted to the optimized ketoprofen enteric coating tablet and found to be smooth surface. In vivo imaging studies revealed that tablets remained in the stomach for $8 \mathrm{~h}$ for famotidine and $12 \mathrm{~h}$ in intestinal region for ketoprofen tablet. DSC studies revealed that there was no interaction between the drug and excipients used for the formulation development.
\end{abstract}

Keywords: Famotidine; Ketoprofen; Floating mini tablets; Enteric coated mini tablet; COX-I enzyme inhibition; $\mathrm{H}_{2}$ receptor antagonist and NSAID

\section{Introduction}

The present study was based on the FDA suggested system for humans, according to the Center for Drug Evaluation and Research (CDER) regulates the combination of products has been divided based on the dosage form preparation, that include a product contained two or more drugs that is known as fixed combination according to the section 21 CFR 300.50 [1]. The final product contains two more regulated components like drug/device, drug/biologic, device/biologic and drug/ device/biologic called as combination product and without biologic/ device that is not a combination product according to the act 21 CFR 3.2 (e) [2]. The present work was developed according to the act 21 CFR 300.50 , There is evidence that fixed-combination medicines has shown greater therapeutic outcomes in patients with communicable diseases such as HIV [3] or tuberculosis [4] (TB), other chronic diseases, such as hypercholesterolaemia [5] and rheumatoid and osteo arthritis [6]. The system fixed combination is not only provide the therapeutic out come and also reduce the drug related side effects upon the addition of another drug and reduce the cost effect on the final product according to the budget impact model [6].

The present work was mainly followed budget impact model system used to prepare fixed combination product of ketoprofen and famotidine used to treat upper gastro intestinal ulcers in patients with chronic inflammatory diseases like rheumatoid and osteo arthritis . In this case those are the patients treated with ketoprofen longterm, it would cause gastric ulcers in the stomach by the inhibition of prostaglandin E2 (PGE2), it leads to produce the high acid levels in the stomach and also reduction of prostaglandin $\mathrm{I}_{2}\left(\mathrm{PGI}_{2}\right)$ leads to suppress the gastric mucosal secretion in the GIT [7]. Here, upon the addition of famotidine reduce the gastric acid secretion by the inhibition of $\mathrm{H}_{2}$ receptor and recently FDA was approved a product of fixed combination of NSAID and $\mathrm{H}_{2}$ receptor antagonist (DUXIS) [8]. The delivery of drug design was based on the theoritical mechanism and the solubility property of the both drugs should be considered. According to the theoretical mechanism, famotidine was required initially for the suppression of acid levels in the stomach and special character of the famotidine has shown the suppression of the acid within the $1 \mathrm{~h}$ and which is highly soluble in stomach $\mathrm{pH}$, then the ketoprofen was programmed to release in the intestine and also which is having greater solulity in the alkaline $\mathrm{pH}$, it leads to improve the absorption levels in the body. The programmed drug delivery was achieved by the mini tablets encapsulation system. In this approach famotidine was designed for floating effervescent sustained mini tablet and ketoprofen was designed for enteric coated sustained mini tablet. It was designed with different rate controlling hydrophilic swellable polymers (HPMC K15M and HPMC K100M) by direct compression method and final optimized formulation was encapsulated in to the (00) size capsule,

\section{Materials and Method}

Famotidine and ketoprofen were kind gift samples from Dr.

*Corresponding author: Nagaraju Banala, Assistant professor, Department of Pharmaceutics, University College of Pharmaceuical Sciences, Kakatiya University, India Tel: 8099722523; E-mail: mahipalreddydonthi@gmail.com; bnrpharmacy@gmail.com

Received September 03, 2015; Accepted October 15, 2015; Published October 22, 2015

Citation: Donthi MR, Dudhipala NR, Komalla DR, Suram D, Banala N (2015) Preparation and Evaluation of Fixed Combination of Ketoprofen Enteric Coated and Famotidine Floating Mini Tablets by Single Unit Encapsulation System. J Bioequiv Availab 7: 279-283. doi:10.4172/jbb.1000254

Copyright: @ 2015 Donthi MR, et al. This is an open-access article distributed under the terms of the Creative Commons Attribution License, which permits unrestricted use, distribution, and reproduction in any medium, provided the original author and source are credited. 
Reddy's laboratories, Hyderabad, India. HPMC $\mathrm{K}_{15} \mathrm{M}$, HPMC $\mathrm{K}_{100} \mathrm{M}$ purchased from Sigma Aldrich chemicals Pvt Ltd, Mumbai, India. Methanol and all other chemicals were analytical grade and purchased from Merck, Mumbai, India.

\section{Method}

Preparation of famotidine floating mini tablets and ketoprofen enteric coated mini tablets: Famotidine floating mini tablets and ketoprofen enteric coated mini tablets were formulated individually with HPMC $\mathrm{K}_{15} \mathrm{M}$ and $\mathrm{HPMC} \mathrm{K}_{100} \mathrm{M}$ polymers and observed individual polymer effect on the drug release. Each famotidine mini tablet contained $10 \%$ of sodium bi carbonate and remaining tablet weight adjusted in both formulations with Avicel pH 101 grade polymer as a bulking agent. All the excipients were mixed in a mortar. The blend was mixed with required quantities of lubricant (talc) and glidant (Magnesium stearate) and passed through the sieve \#100, final blend was compressed to form tablets in a 16 station rotary tablet machine (Riddhi, Ahmedabad, India) using $3 \mathrm{~mm}$ round flatted punches. The total weight of each tablet was $50 \mathrm{mg}$ and containing $10 \mathrm{mg}$ of famotidine in floating mini tablets. $20 \mathrm{mg}$ of ketoprofen present in enteric coated mini tablets. The composition of floating famotidine floating and enteric coated mini tablets of ketoprofen formulations were shown in Tables 1 and 2 .

\section{Pre compression evaluation parameters}

Solubility study: The saturation solubility method was selected and it was conducted in different $\mathrm{pH}$ buffer medias including water and methanol. In this method incubator shaker was used for shaking at $200 \mathrm{rpm}$ for 24 hours at $37^{\circ} \mathrm{C}$. After 24 hours the drug solution was centrifuged at $2000 \mathrm{rpm}$ then the supernatant solution was separated and which was diluted with suitable media $[9,10]$. And the absorbance was analysed by UV Visible spectrophotometer (Systronics 117).

Drug excipient compatibility studies by differential scanning calorimetry: The interaction between the drug and excipients studies was determined by DSC (DSC-4000, Perkin Elmer, USA). The study was performed based on the reported USP melting point of the both

\begin{tabular}{|l|c|c|c|c|c|c|}
\hline Ingredients $\mathbf{( m g )}$ & $\mathbf{K} 1$ & $\mathbf{K 2}$ & $\mathbf{K} 3$ & $\mathbf{K 4}$ & $\mathbf{K 5}$ & K6 \\
\hline Ketoprofen & 100 & 100 & 100 & 100 & 100 & 100 \\
\hline HPMC $\mathbf{K}_{\mathbf{1 5}} \mathbf{M}$ & 50 & 100 & 125 & - & - & - \\
\hline HPMC $\mathbf{K}_{\mathbf{1 0 0}} \mathbf{M}$ & - & - & - & 25 & 50 & 100 \\
\hline Avicel pH 101 & 100 & 50 & 25 & 125 & 100 & 50 \\
\hline Magnesium stearate & 8 & 8 & 8 & 8 & 8 & 8 \\
\hline Talc & 10 & 10 & 10 & 10 & 10 & 10 \\
\hline Total tablet weight & 270 & 270 & 270 & 270 & 270 & 270 \\
\hline
\end{tabular}

Each tablet divided into 5 mini tablets $(54 \mathrm{mg} \times 5$ tablets $=270 \mathrm{mg}$ )

Table 1: Composition of ketoprofen core tablets

\begin{tabular}{|l|c|c|c|c|c|c|}
\hline Ingredients (mg) & F1 & F2 & F3 & F4 & F5 & F6 \\
\hline Famotidine & 20 & 20 & 20 & 20 & 20 & 20 \\
\hline NaHCO $_{3}$ & 10 & 10 & 10 & 10 & 10 & 10 \\
\hline HPMC K15M & 10 & 20 & 25 & - & - & - \\
\hline HPMC K100M & - & - & - & 5 & 10 & 20 \\
\hline M.C.C pH 101 & 52 & 42 & 37 & 57 & 52 & 42 \\
\hline Talc & 4 & 4 & 4 & 4 & 4 & 4 \\
\hline Magnesium stearate & 4 & 4 & 4 & 4 & 4 & 4 \\
\hline Total tablet weight & 100 & 100 & 100 & 100 & 100 & 100 \\
\hline
\end{tabular}

Each tablet divides into 2 mini tablets (50 mg x 2=100 mg)

Table 2: Composition of famotidine floating tablets. pure drugs and with their excipients. If the change of melting point is found there was a incompatibility is present in between drugs and their excipients, it indicates the formulation is not suitable with that particular excipients.

The other pre compression evaluation parameters include angle of repose by using fixed funnel method, Carr's index and Hausner's ratio were performed for both drugs according to the USP specifications.

In vitro buoyancy studies of famotidine: The reported Invitro buoyancy studies were described by Rosa et al. That buoyancy studies were performed in a $100 \mathrm{ml}$ beaker containing $0.1 \mathrm{~N} \mathrm{HCl}$. According to the specified method the time required for the tablet was raised from the bottom to surface in the $0.1 \mathrm{~N} \mathrm{HCl}$ is known as floating lag time and the time period, the tablet remained buoyant is called Total Floating Time (TFT).

In vitro release study of famotidine: The release study was performed based on the solubility of drug and according to the theoretical mechanism the famotidine required to release in the stomach region is important and the media $900 \mathrm{ml}$ of $0.1 \mathrm{~N} \mathrm{HCl}$ was selected. Invitro release study was conducted with USP-II Paddle apparatus (TDT-08L, Electrolabs, India) at $50 \mathrm{rpm}$ with $37 \pm 0.5^{\circ} \mathrm{C}$.

In vitro release study of ketoprofen: The drug release was performed based on the solubility study and it require the release at the intestine according to the formulation strategy, the Invitro release study was conducted by using USP type-II dissolution apparatus with $50 \mathrm{rpm}$ at $37 \pm 0.5^{\circ} \mathrm{C}$.

Preparation of enteric coated mini tablets of ketoprofen: The prepared core tablets were coated with Eudragit L-100 and composition is shown in Table 3 . The coating solution was prepared by taking the solvent in a glass beaker and adding the pre-weighed quantity of Eudragit L 100 in small quantities at a time. Mixing was ensured by means of a mechanical stirrer. After complete solubilisation of the polymer then plasticizer and pre solubilised, colour was incorporated into the solution and kept for overnight stirring. The solution was coated at different ratios of EudragitL-100 on the optimized core formulation of the ketoprofen.

Characterization of enteric coated tablets: The enteric coated tablets characterization includes percentage of weight gain upon coating, hardness, thickness of the tablets were performed. Final optimized formulation was carried out for the SEM and X-ray studies.

Scanning electron microscopy (SEM): The SEM study was conducted on the optimized enteric coating tablet. The tablet surface was observed. if any defects on tablet coating, it was shown microscopically, the pores are present on surface or uneven distribution of coating solution that indicates like rough surface on the tablet.

In vitro dissolution study of optimized enteric coated formulation of ketoprofen: The study was carried out for $15 \mathrm{~h}$ with USP type-II dissolution apparatus and the procedure for first $3 \mathrm{~h}$ release was conducted in $0.1 \mathrm{~N} \mathrm{HCl}$ for gastric challenge and then the release continued with 6.8 phosphate buffer up to $15 \mathrm{~h}$.

In vivo radiographic study: The in vivo radiographic study was carried out with single mini tablet of famotidine and enteric coated ketoprofen mini tablet in 3 healthy human volunteers about the age 25 and weight $60 \mathrm{kgs}$. In this in vivo radiographic study famotidine designed for floating specificity in stomach and ketoprofen was designed for enteric coating specificity for intestine. The radio opaqueness was obtained by using barium sulphate instead of drug. 


\section{Results and Discussion}

\section{Pre compression evaluation studies}

\section{Solubility study:}

Solubility study of ketoprofen and famotidine: Solubility studies of drugs were performed in different media and results shown in Figure 1. Ketoprofen is the class-II and famotidine is the class-IV drug, which are having the $\mathrm{pH}$ dependent solubility property. Hence, the solubility study was performed in the different $\mathrm{pH}$ of the media. From the results, $\mathrm{pH}$ increase towards alkaline, solubility were increased for ketoprofen and as the $\mathrm{pH}$ decrease, the solubility of the drug will be increased for famotidine. Therefore, ketoprofen was highly soluble $\mathrm{pH}$ 7.4 phosphate buffer and famotidine was highly soluble in $0.1 \mathrm{~N} \mathrm{HCl}$ and both drugs were having lesser solubility in water.

Drug excipient compatibility study by differential scanning colorimetry: The DSC thermograms of pure famotidine, pure ketoprofen, combination of both drugs and physical mixture of optimized formulation are shown in Figure 2. A sharp endothermic peaks of famotidine and ketoprofen were observed at $164.7^{\circ} \mathrm{C}$ (reported $160-170^{\circ} \mathrm{C}$ ) and $96.5^{\circ} \mathrm{C}$ (reported $92-96^{\circ} \mathrm{C}$ ) respectively. In case of combination of drugs ketoprofen and famotidine showed sharp endothermic peaks at $96.7^{\circ} \mathrm{C}$ and $170.02^{\circ} \mathrm{C}$ respectively. The optimized formulation (physical mixing) exhibited similar type behaviour at respective temperature. Therefore, the DSC studies revealed that no interaction between the drug and other excipients.

Pre compression evaluation results of ketoprofen and famotidine: The pre compression parameters were given satisfactory results according to the pharmacopeia and presented in table 4 . The angle of repose values suggested as good flow property, the compressibility values were suggested good and the Hauner's ratio $<1.2$ suggested that is good flow was found.

The post compression evaluation parameters values were suggested satisfactory results according to the pharmacopeial specification, the $\%$ drug content range was found (97\%-102\%) in all the formulations table 5 .

\begin{tabular}{|c|c|}
\hline Ingredient & Quantity \\
\hline Eudragit L100 & $6.25 \mathrm{gr}$ \\
\hline Dibutyl phthalate & 0.625 \\
\hline Isopropyl alcohol+acetone & $50+50$ \\
\hline Talc & 3.125 \\
\hline $\mathrm{TiO}_{2}$ & 1.2 \\
\hline wt. gain & $\mathbf{1 5 \%}$ \\
\hline
\end{tabular}

Table 3: Composition of optimized coating solution.

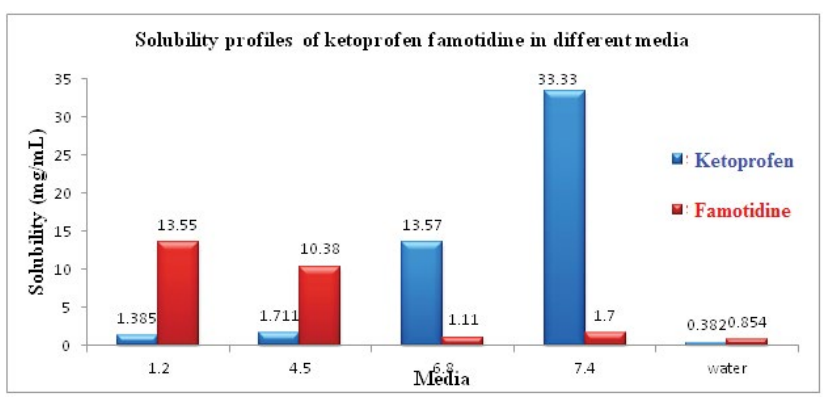

Figure 1: Solubility study of ketoprofen and famotidine in different media (Mean $\pm S D, n=3$ ).

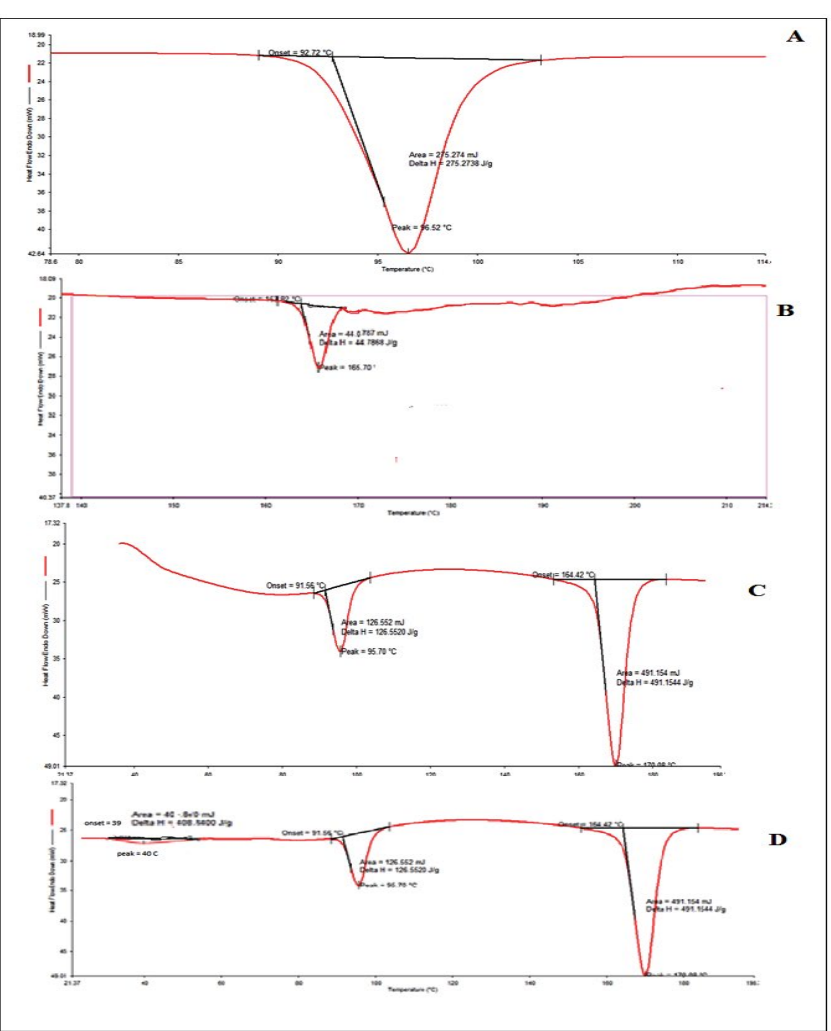

Figure 2: DSC thermogram of A) Ketoprofen pure drug, B) Famotidine pure drug, C) Physical mixture of two drugs (1:1 ratio) and D) Optimized formulation (physical mixing).

The post compression evaluation parameters were given good results as per the USP and the content uniformity was found best in the all formulations (97-100\%) (Table 6).

From the in vitro buoyancy studies, floating lag time of all formulations were found $(09-14 \mathrm{sec})$ with total floating time of formulation has shown $>12 \mathrm{~h}$ (Table 7 ).

In vitro drug release study of ketoprofen formulations: In this Invitro release of all formulations were carried out with $\mathrm{pH} 6.8$ phosphate buffer. That the comparative profile K5 has shown better release $100.5 \%$ within $12 \mathrm{~h}$ (Figure 3). K5 formulation was carried out for coating.

In vitro drug release study of famotidine floating mini tablets: In this in vitro release study all the formulations were carried out in the 0.1 $\mathrm{N} \mathrm{HCl}$. From in that results $\mathrm{F} 5$ was gave better release $98.06 \%$ within 12 $\mathrm{h}$ time period (Figure 4 ).

Characterization of enteric coated formulation: In this characterization, initially the coating solution was optimized. Then the formulation carried out for physical evaluation parameters and finally in vitro release was performed.

Physical evaluation parameters of enteric coated ketoprofen mini tablets: The common evaluation parameters were conducted after coating and the results has shown in table 8.

The optimized ketoprofen and famotidine mini tablets filled into capsule as single unit dosage form and dissolution was carried out. The optimized K5 study conducted first $3 \mathrm{~h}$, further release study carried 
Citation: Donthi MR, Dudhipala NR, Komalla DR, Suram D, Banala N (2015)Preparation and Evaluation of Fixed Combination of Ketoprofen Enteric Coated and Famotidine Floating Mini Tablets by Single Unit Encapsulation System. J Bioequiv Availab 7: 279-283. doi:10.4172/jbb.1000254

\begin{tabular}{|c|c|c|c|c|c|c|c|}
\hline Formulation & $\mathrm{Cl}$ & Angle of repose & Hausner's ratio & Formulation & $\mathrm{Cl}$ & Angle of repose & Hausner's ratio \\
\hline K1 & 15.4 & $28.4^{\circ}$ & 1.17 & FF1 & 15.3 & $29.3^{\circ}$ & 1.17 \\
\hline K2 & 12.3 & $29.5^{\circ}$ & 1.15 & FF2 & 14.5 & $28.6^{\circ}$ & 1.05 \\
\hline K3 & 11.2 & $28.4^{\circ}$ & 1.18 & FF3 & 12.6 & $29.5^{\circ}$ & 1.18 \\
\hline K4 & 13.7 & $29.8^{\circ}$ & 1.08 & FF4 & 12.4 & $26.6^{\circ}$ & 1.14 \\
\hline K5 & 12.2 & $27.5^{\circ}$ & 1.18 & FF5 & 15.2 & $28.3^{\circ}$ & 1.18 \\
\hline K6 & 14.8 & $29.4^{\circ}$ & 1.14 & FF6 & 11.2 & $27.8^{\circ}$ & 1.17 \\
\hline
\end{tabular}

Post compression evaluation results of ketoprofen and famotidine

Table 4: Pre-compression parameters of ketoprofen and famotidine.

\begin{tabular}{|c|c|c|c|c|c|}
\hline Formulation & Thickness (mm) & Hardness $\left(\mathrm{Kg} / \mathrm{cm}^{2}\right)$ & Weight variation $\mathrm{mg}$ ) & Friability (\%) & Drug content (\%) \\
\hline K1 & $2 \pm 0.3$ & $6.8 \pm 0.02$ & $49 \pm 1.6$ & $0.27 \pm 0.07$ & $98 \pm 1.32$ \\
\hline K2 & $2.2 \pm 0.2$ & $6.6 \pm 0.05$ & $54 \pm 1.2$ & $0.32 \pm 0.04$ & $100 \pm 0.8$ \\
\hline 3 & $2.19 \pm 0.4$ & $6.8 \pm 0.05$ & $53 \pm 1$ & $0.25 \pm 0.02$ & $101 \pm 1.1$ \\
\hline K4 & $2.2 \pm 0.3$ & $7 \pm 02$ & $50 \pm 0.6$ & $0.27 \pm 0.04$ & $97 \pm 0.79$ \\
\hline K5 & $2.3 \pm 0.2$ & $6.8 \pm 0.04$ & $49 \pm 1$ & $0.36 \pm 0.07$ & $99 \pm 0.29$ \\
\hline K6 & $2.2 \pm 0.5$ & $6.5 \pm 0.03$ & $52 \pm 1.2$ & $0.31 \pm 0.08$ & $101 \pm 1.3$ \\
\hline
\end{tabular}

Table 5: Physico-chemical parameters of ketoprofen core tablets.

\begin{tabular}{|c|c|c|c|c|c|}
\hline Formulation & Thickness (mm) & Hardness $\left(\mathrm{Kg} / \mathrm{cm}^{2}\right)$ & Weight Variation (mg) & Friability (\%) & Drug content (\%) \\
\hline $\mathrm{F} 1$ & $2.0 \pm 0.01$ & $5.0 \pm 0.05$ & $54 \pm 1.1$ & $0.41 \pm 0.04$ & $98 \pm 1.02$ \\
\hline $\mathrm{F} 2$ & $2.27 \pm 0.03$ & $5.5 \pm 0.04$ & $51 \pm 1.5$ & $0.32 \pm 0.01$ & $100 \pm 1.33$ \\
\hline F3 & $2.19 \pm 0.05$ & $5.0 \pm 0.06$ & $49 \pm 0.91$ & $0.53 \pm 0.04$ & $101 \pm 0.78$ \\
\hline $\mathrm{F} 4$ & $2.20 \pm 0.02$ & $4.8 \pm 0.05$ & $51 \pm 0.75$ & $0.38 \pm 0.04$ & $97 \pm 0.56$ \\
\hline F5 & $2.31 \pm 0.04$ & $5.2 \pm 0.02$ & $49 \pm 1.3$ & $0.45 \pm 023$ & $100 \pm 0.12$ \\
\hline F6 & $2.28 \pm 0.05$ & $5.5 \pm 0.04$ & $50 \pm 0.79$ & $0.52 \pm 0.04$ & $98 \pm 0.79$ \\
\hline
\end{tabular}

In vitro buoyancy study

Table 6: Physico-chemical parameters of famotidine floating tablets

\begin{tabular}{|c|c|c|}
\hline Formulation code & Lag time $\mathbf{( s e c )}$ & Total floating time (h) \\
\hline F1 & 14 & $>12$ \\
\hline F2 & 11 & $>12$ \\
\hline F3 & 09 & $>12$ \\
\hline F4 & 13 & $>12$ \\
\hline F5 & 10 & $>12$ \\
\hline F6 & 10 & $>12$ \\
\hline
\end{tabular}

Table 7: In vitro buoyancy studies of famotidine floating tablets.

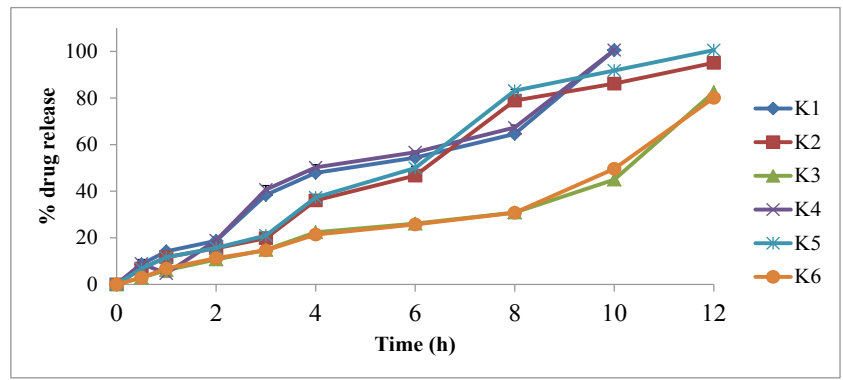

Figure 3: In vitro release profiles of ketoprofen core tablets (Mean $\pm S D, n=3$ ).

out in $\mathrm{pH} 6.8$ phosphate buffer upto $15 \mathrm{~h}$ and has shown $97.5 \pm 2.31 \%$ release. F5 formulation showed $98.02 \pm 2.79 \%$ in $12 \mathrm{~h}$ in $0.1 \mathrm{~N} \mathrm{HCl}$ (Figure 5).

Scanning electron microscopy (SEM) study of optimized formulation: This study was performed before and after dissolution of the coating tablets for observation of external surface of the tablet. Before dissolution the SEM was shown clear and smooth surface on the coated tablet figure 12. After $6 \mathrm{hrs}$ of dissolution the SEM was found rough surface due to the effect of erosion (Figure 6).

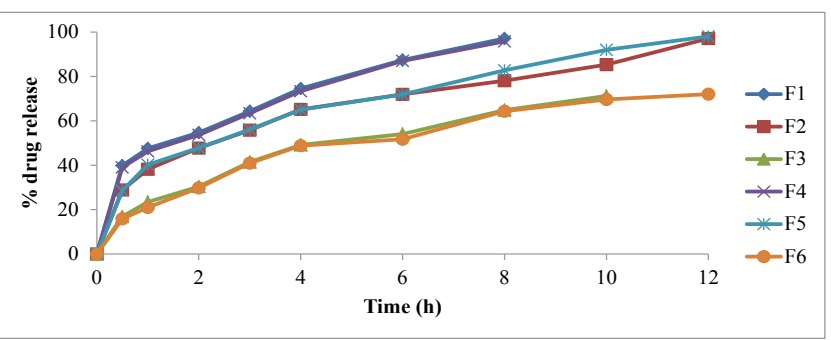

Figure 4: In vitro release profiles of famotidine floating tablets in $0.1 \mathrm{~N} \mathrm{HCl}$ $($ Mean $\pm S D, n=3$ )

\begin{tabular}{|c|c|c|c|}
\hline $\begin{array}{c}\text { Polymer } \\
\text { concentration }\end{array}$ & Weight Gain & $\begin{array}{c}\text { Hardness } \\
\left(\mathbf{k g} / \mathbf{c m}^{\mathbf{2}}\right)\end{array}$ & Process time (min) \\
\hline \multirow{2}{*}{$6 \%$} & $6.25 \%$ & 6.09 & 50 \\
\cline { 2 - 4 } & $6.94 \%$ & 8.09 & 60 \\
\cline { 2 - 4 } & $6.05 \%$ & 11.45 & 90 \\
\hline
\end{tabular}

Comparative drug release profile of F5 and K5 formulations in capsule as single unit

Table 8: Evaluation results of enteric coated tablets.

In vivo radiographic study: The in vivo radio graphic study was carried out with single mini tablet of $\mathrm{K} 5$ and $\mathrm{F} 5$ optimized formulation in capsule form and contain $10 \% \mathrm{w} / \mathrm{w}$ of radio opaque substance $\left(\mathrm{BaSO}_{4}\right)$. From the results, of in vivo imaging studies, tablets remained in the stomach for $8 \mathrm{~h}$ for famotidine and $12 \mathrm{~h}$ in intestinal region for ketoprofen (Figure 7).

\section{Conclusion}

These fixed combination research was beneficial for the patients 
Citation: Donthi MR, Dudhipala NR, Komalla DR, Suram D, Banala N (2015)Preparation and Evaluation of Fixed Combination of Ketoprofen Enteric Coated and Famotidine Floating Mini Tablets by Single Unit Encapsulation System. J Bioequiv Availab 7: 279-283. doi:10.4172/jbb.1000254

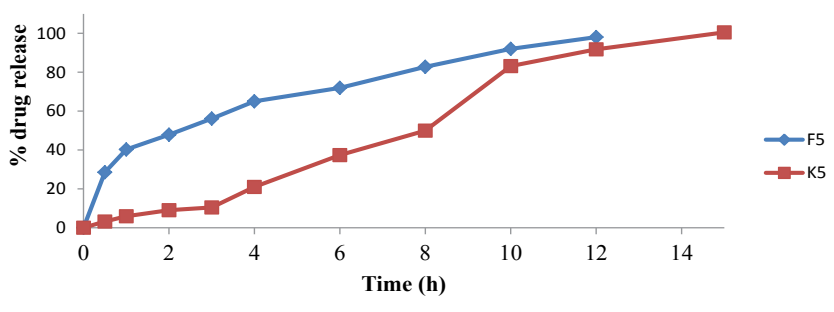

Figure 5: In vitro comparative release profile of optimized F5 and K5 formulations in single capsule formulation.

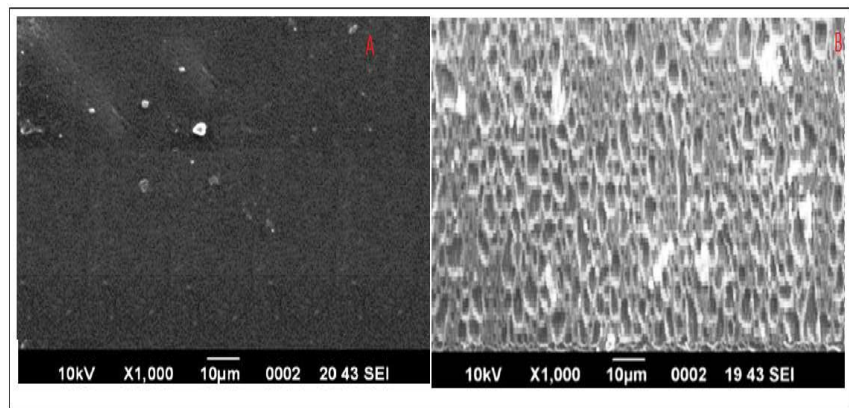

Figure 6: SEM images of ketoprofen enteric coated tablets $(A)$ before dissolution and $(\mathrm{B})$ after dissolution.
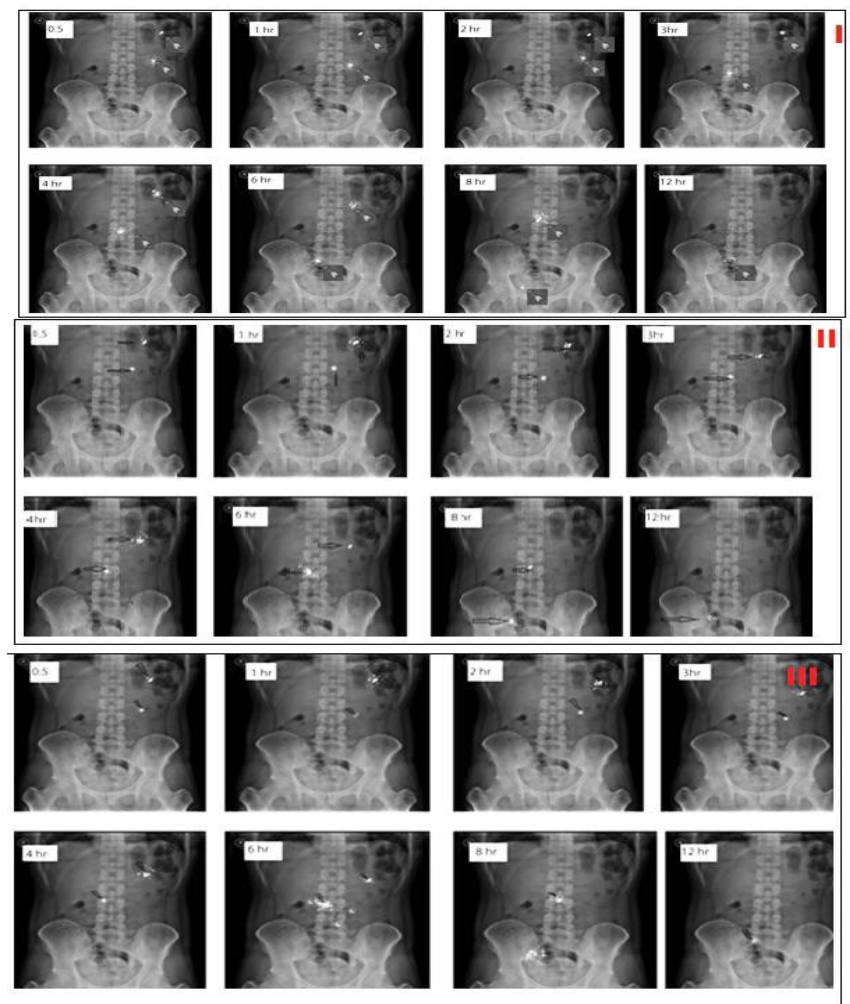

Figure 7: In vivo radio graphic study images of famotidine and ketoprofen in capsule system after X-ray exposure in I-Volunteer-1, II-volunteer-2 and III-volunteer-3. those are suffered with chronic and communicable diseases. Preprogrammed and site specific delivery was easy to achieve. The pre compression and post compression parameters were gave satisfactory results and the final optimized formulations F5 (98.06\%) and also K5 has shown better release $(97.5 \%)$. the Invitro total floating time was found $>12 \mathrm{~h}$. SEM images has shown smooth surface after coating and finally in vivo radiographic study was concluded from the three human volunteers that the famotidine was retained $8 \mathrm{~h}$ in the stomach and ketoprofen was found up to $12 \mathrm{~h}$ time.

\section{References}

1. FDA (2015) Food and drug administration department of health and human services sub chapter-D-Drugs for human use, titile-21: 5 .

2. FDA (2015) Food and drug administration department of health and human services sub chapter a-general title 21 .

3. (2010) Australian government department of health and ageing. Compliance medicines working group report to pharmaceutical benefits advisory committee.

4. Llibre JM, Arribas JR, Domingo P, Gatell JM, Lozano F, et al. (2011) Clinical implications of fixed-dose coformulations of antiretrovirals on the outcome of HIV-1 therapy. AIDS 25: 1683-1690.

5. Blomberg B, Spinaci S, Fourie B, Laing R (2001) The rationale for recommending fixed-dose combination tablets for treatment of tuberculosis. Bull World Health Organ 79: 61-68.

6. Kuan R, Holt RJ, Johnson KE, Kent JD, Peura DA, et al. (2013) Budget impact modeling for a single-tablet formulation of ibuprofen and famotidine for prevention of upper gastrointestinal ulcers in patients with osteoarthritis and/or rheumatoid arthritis. Clin Ther 35: 321-332

7. Soll AH (1980) Specific inhibition by prostaglandins E2 and 12 of histaminestimulated [14C] aminopyrine accumulation and cyclic adenosine monophosphate generation by isolated canine parietal cells. J Clin Invest 65 : 1222-1229.

8. (2012) Duexis (ibuprofen and famotidine) [package insert]. Deerfield, IL. Horizon Pharma USA, Inc.

9. Kumar Maheshwari R, Indurkhya A (2010) Formulation and evaluation of aceclofenac injection made by mixed hydrotropic solubilization technique. Iran J Pharm Res 9: 233-242.

10. Badjatya JK, Bodla RK, Moon UB (2011) Enhancement of solubility of fenofibrate by using different solubilization techniques. Asian J Pharm Life Sci 1: $144-148$. 